\title{
Study on Acoustic Emission Characteristics of Different Felsic Metagabbros Under Hydraulic Coupling
}

\author{
Tongzhao Zhang $(\mathbb{D} \cdot$ Hongguang Ji $\cdot$ Xiaobo Su $\cdot$ Daolu Quan $\cdot$ \\ Zhou Zhang $\cdot$ Jinzhe Li
}

Received: 9 September 2021 / Accepted: 17 January 2022 / Published online: 27 January 2022

(C) The Author(s) 2022

\begin{abstract}
The mechanical properties of the deep rock are impacted not only by the complicated stress environment but also by the mineral composition. To reveal the relationship between mineral development characteristics and acoustic emission signals in the mechanical evolution of deep rocks, metagabbros with different feldspar mineral development were subjected to acoustic emission tests under hydraulic coupling. The characteristic parameter of acoustic emission signals and their correlation characteristics were investigated. The results showed that the mechanical property of the metagabbro with feldspar mineral development was better than that without feldspar mineral. The metagabbro with feldspar mineral development had much larger AE ringing counts and absolute energies, as well as stronger rock brittleness features than that without feldspar mineral development. With increasing feldspar mineral content in metagabbro, the AE signals showed a longer duration and a higher amplitude. During the unstable crack propagation stage, metagabbro without feldspar mineral development exhibited four peak
\end{abstract}

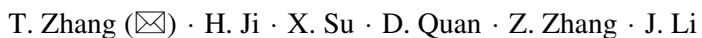
School of Civil and Resource Engineering, University of Science and Technology Beijing, Beijing 100083, China e-mail: yfzr2011@163.com

T. Zhang · H. Ji · X. Su - D. Quan - Z. Zhang · J. Li Beijing Key Laboratory of Urban Underground Space Engineering, University of Science and Technology Beijing, Beijing 100083, China frequency ranges, while that with feldspar mineral development displayed five frequency ranges. The metagabbro with nonuniform feldspar mineral development had more pores and microcracks than that with uniform mineral development. The permeability of the rocks was highly correlated with the uniformity of mineral development. This study provides a theoretical foundation for monitoring and early warning of water inrush risk in deep rock engineering.

Keywords Acoustic emission · Hydraulic coupling · Rock mechanics $\cdot$ Peak frequency

\section{Introduction}

The depth of underground mining is increasing with increasing depletion of shallow resources (Xie 2019; Cai et al. 2019; Li et al. 2017). Deep rocks are subjected to high in-situ stress as well as high osmotic pressures, leading hydraulic coupling (Liu and Zhang 2008). The osmotic pressure has the obvious effect of accelerating the crack propagation, which in turn deteriorates the mechanical property of rock, causing some engineering risk such as water inrush (Zhao et al. 2014; Zhang et al. 2019a). Therefore, the study of the deep rock mechanics under hydraulic coupling is critical for underground engineering.

Existing research focused on the permeability of rock under hydraulic coupling (Wang et al. 2001; Hu 
et al. 2014; Wang et al; 2012a). Zhang et al. (2020a, b, c) conducted triaxial compression permeability experiments on sandstone using a rock top multi-field coupled tester to reveal the permeability law of rocks during the stress-strain process. Zhang et al. (2019b) discovered that after the loss of bearing capacity, the permeability of granite increased exponentially with decreasing surrounding pressure. Wang et al. (2018) analyzed the energy evolution law and permeability characteristics of deep coal rock by triaxial cyclic loading and unloading tests. Liu et al. (2018) investigated the relationship between the internal fracture and permeability on sandstone. The type, size, arrangement, and bonding degree of minerals in the rock had a remarkable effect on its physical and mechanical properties (Zhao et al. 2014; Cowie and Walton 2018; Ömer Ündül 2016). However, the studies considering the development characteristics of rock minerals under hydraulic coupling are rarely reported.

The process of microcrack initiation, expansion, and penetration in rock materials is accompanied by the release of energy, resulting in acoustic emission (AE) phenomenon (Zhang et al. 2015; Li et al. 2017). It had been demonstrated that the $\mathrm{AE}$ signals exhibit certain evolutionary characteristics in the rock fracture process (Ji et al. 2015; Li et al. 2018; Zeng et al. 2017; Song et al. 2018, 2019; Pei et al. 2019). AE technology could monitor the development of microcracks in rock in real time and can effectively discriminate and predict the physical properties, stability state, and rupture degree, thus providing a discriminative basis for disaster prevention and control ( $\mathrm{Ji}$ and $\mathrm{Lu} 2015$; Song et al. 2020). Therefore, AE signals can be used to accurately predict the damage and rupture of rocks with different mineral development.

In this study, the hydraulic coupling test of metagabbros with different feldspar mineral developments was carried out, and the resulting AE signals during the rock fracture process were monitored. The evolution of stress and $\mathrm{AE}$ characteristic signals of metagabbro were analyzed. The distribution characteristics between the $\mathrm{AE}$ ringing count and its absolute energy, amplitude, and duration for different metagabbros were explored. The characteristics of AE peak frequencies and permeability in different metagabbros were investigated. This study would have important guiding significance and reference value for the construction design in deep rock engineering.

\section{Experimental}

Metagabbro samples were obtained from subsurface layers at 800-1200 m in Laizhou District, Shandong Province, China and composed of hornblende, feldspar, quartz, biotite chlorite, and other minerals. The rock matrix comprised dark minerals such as hornblende and biotite, as shown in Fig. 1. According to the standards, $\Phi 50 \mathrm{~mm} \times 100 \mathrm{~mm}$ cylindrical rock samples were processed in the laboratory. Metagabbro with different felsic developments were chosen for the test, as shown in Fig. 2. Metagabbro sample A was distinguished by feldspar nondevelopments. Metagabbro samples $\mathrm{B}$ and $\mathrm{C}$ were characterized by different feldspar developments. The mineral development characteristics of metagabbro samples A and B were more uniform than those of metagabbro sample $\mathrm{C}$. However, the feldspar minerals of metagabbro samples $\mathrm{B}$ and $\mathrm{C}$ developed more than those of metagabbro sample A. Matrixes of different metagabbros have the same microstructures by comparing the microscopic slices. To ensure that the original fractures and micropores of the rock sample were filled with water, the samples were kept in a pressure chamber for $48 \mathrm{~h}$.

The triaxial test was conducted using a TAW-2000 computer control electro-hydraulic servo, with the maximum lateral limit, maximum penetration pressure, and maximum axial load of $100 \mathrm{MPa}, 60 \mathrm{MPa}$, and $2000 \mathrm{kN}$, respectively. A PCI-2 AE instrument was used as the AE device. Figure 3 shows the test system. The resonant frequencies of the probes in the experiment were 60 and $150 \mathrm{kHz}$. The main amplifier of the $\mathrm{AE}$ test system was set to $40 \mathrm{~dB}$ with the threshold value of $45 \mathrm{~dB}$.

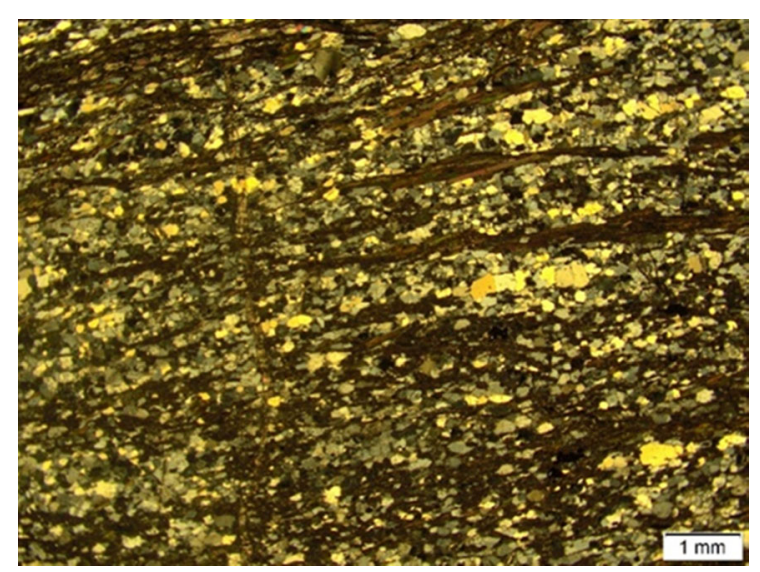

Fig. 1 Polarized microphotographs of rock sample 


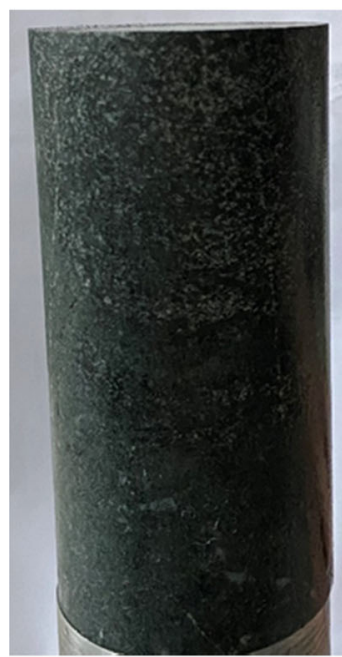

(A) Feldspar nondevelopment

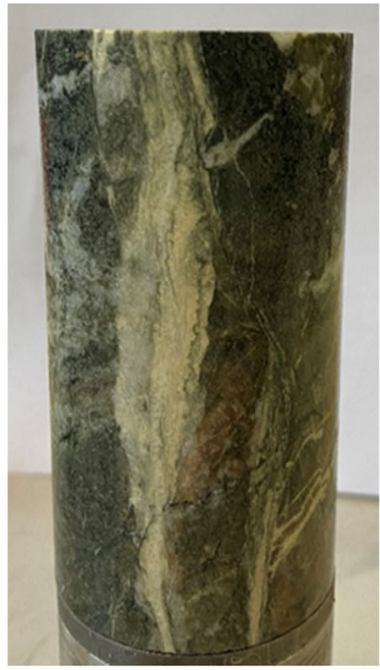

(B) Feldspar nonuniform development

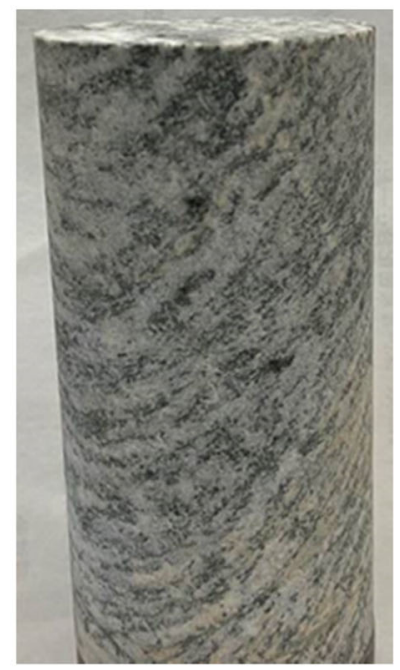

(C) Uniform feldspar development

Fig. 2 Metagabbro test rock sample

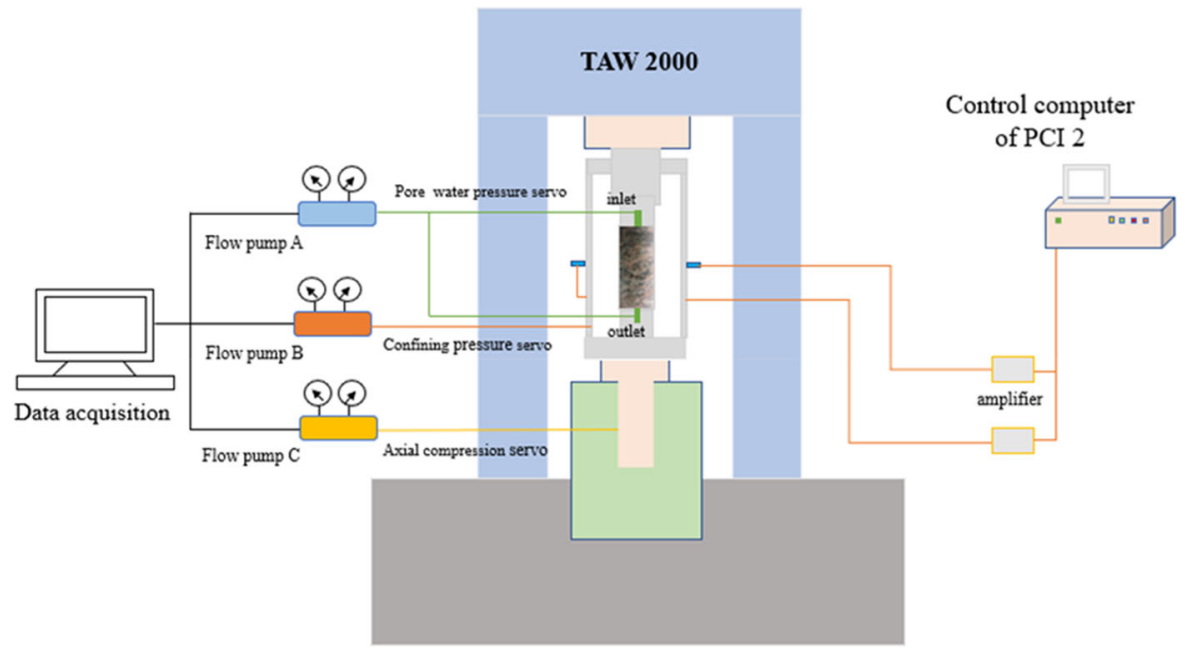

Fig. 3 Testing systems

During the test, the AE sensors were taped to the side of the pressure cylinder. Vaseline petroleum jelly was smeared on the contact surface of the AE sensor and the pressure cylinder to improve hydraulic coupling and reduce attenuation of the AE signal.

The confining pressure and water pressure were designated as $20 \mathrm{MPa}, 4 \mathrm{MPa}$, respectively. The prestress of $1 \mathrm{kN}$ was applied to the rock sample to ensure it was in full contact with the loader indenter, and this could further eliminate the noise generated during the contact process of the indenter and the sample. The pressure test machine and $\mathrm{AE}$ acquisition equipment were simultaneously turned on. The triaxial tests were conducted under axial deformation, with a loading speed of $0.01 \mathrm{~mm} / \mathrm{min}$.

\section{Results of Stress-Strain Curves}

According to the stress-strain curve, the loading process before the peak is divided into the four stages: the compaction stage I, the linear elastic stage II, the 
stable crack propagation stage III, and the unstable crack propagation stage IV. The characteristic strength can be identified based on the corresponding characteristic points of the four stages. Stage I is the compression closure stage with microcracks in the rock, and the upper limit stress is the rock closure strength $\sigma_{\mathrm{cc}}$. Stage II is the linear elastic deformation stage, with the rock initiation strength $\sigma_{\mathrm{ci}}$ as the upper limit stress. Stage III is the stable fracture propagation stage, and the rock damage strength $\sigma_{\mathrm{cd}}$ is the upper limit stress. Stage IV is the unstable crack propagation stage, with the peak rock strength $\sigma_{\mathrm{c}}$ as the upper limit stress. The characteristic strength could be determined by the crack volume strain method proposed by Martin et al. (1994) $\left(\varepsilon_{v}\right.$ and $\varepsilon_{c v}$ are the volume strain and crack volume strain, respectively). This method had the advantages of clear physical meaning and easy applicability and had been widely used in the analysis of conventional triaxial compression test results of brittle rocks (Zhu et al. 2007; Wang et al. 2012b, 2014). Table 1 displays the characteristic strengths of different metagabbros.

Figure 4 shows that the stress-strain curve of metagabbro sample A has four distinct stages, whereas those of metagabbro samples B and C lack stage I. Owing to the heavy proportion of feldspar and quartz minerals, metagabbro samples $\mathrm{B}$ and $\mathrm{C}$ had a high elasticity. Under a confining pressure of $20 \mathrm{MPa}$, the microcracks of metagabbro samples B and C closed, causing challenges to measure its closed strength. Table 1 shows the characteristic strength of different metagabbros. The peak strength, crack initiation strength, damage strength, and elastic modulus of metagabbro samples $\mathrm{B}$ and $\mathrm{C}$ were significantly greater than those of metagabbro sample $\mathrm{A}$, and its Poisson ratio was smaller than that of metagabbro sample A. Moreover, the mechanical properties of metagabbro sample $\mathrm{C}$ were better than that of metagabbro sample $\mathrm{B}$, indicating that the peak strength, cracking strength, damage strength, elastic modulus, and the Poisson ratio of metagabbro were not only related to mineral content, but also related to mineral distribution uniformity.

\section{AE Characteristic Signal of Different Metagabbros}

\subsection{AE Ringing Count}

On the time domain graph of $\mathrm{AE}$ waves, $\mathrm{AE}$ ringing refers to one pulse output per oscillation of the transducer, and thus also refers to the number of oscillations that cross the threshold in the AE waveform signal. It can reflect the propagation degree of micro-cracks in rock. Figure 5 shows the relationship between stress, AE ringing count, and AE accumulative ringing count.

There was almost no AE signal in the elastic stage and stable crack propagation stage for metagabbro, and more AE ringing counts produced in the unstable crack propagation stage. The peak of the AE ringing count lagged behind the stress peak in metagabbro samples A and B. While comparing the AE ringing counts generated during the shear damage, the ringing counts of metagabbro samples $\mathrm{B}$ and $\mathrm{C}$ were higher than that of metagabbro sample A, indicating that the rocks were more brittle. In addition to one peak of the $\mathrm{AE}$ ringing count under the shear failure, the other peak of the $\mathrm{AE}$ ringing count appeared in the unstable crack propagation stage of metagabbro sample B, indicating more complex rupture.

The accumulative ringing counts showed the same trend both for metagabbro samples A and $\mathrm{C}$. The AE accumulative ringing count rose slowly in the elastic and stable crack propagation stages, then rapidly in the unstable crack propagation stage. The accumulative ringing count of metagabbro sample $\mathrm{B}$ revealed a growth inflection point in the stage of unstable crack

Table 1 Characteristic strengths of different metagabbros

\begin{tabular}{lllcccc}
\hline Sample & Poisson rate & Elastic modulus/MPa & $\sigma_{\mathrm{cc}} / \mathrm{Mpa}$ & $\sigma_{\mathrm{ci}} / \mathrm{Mpa}$ & $\sigma_{\mathrm{cd}} / \mathrm{Mpa}$ & $\sigma_{\mathrm{c}} / \mathrm{Mpa}$ \\
\hline A & 0.3 & 98,195 & 23.511 & 72.015 & 93.048 & 201.054 \\
B & 0.23 & 111,783 & - & 96.3 & 161.0 & 240.70 \\
C & 0.12 & 125,882 & - & 168.661 & 191.471 & 283.998 \\
\hline
\end{tabular}




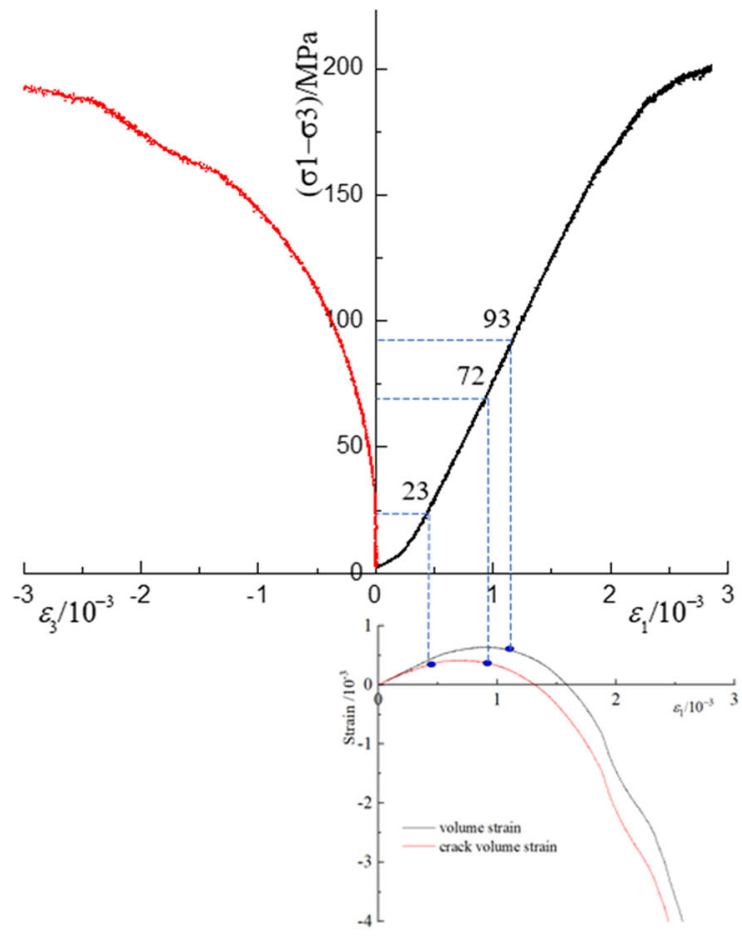

(A) Feldspar nondevelopment

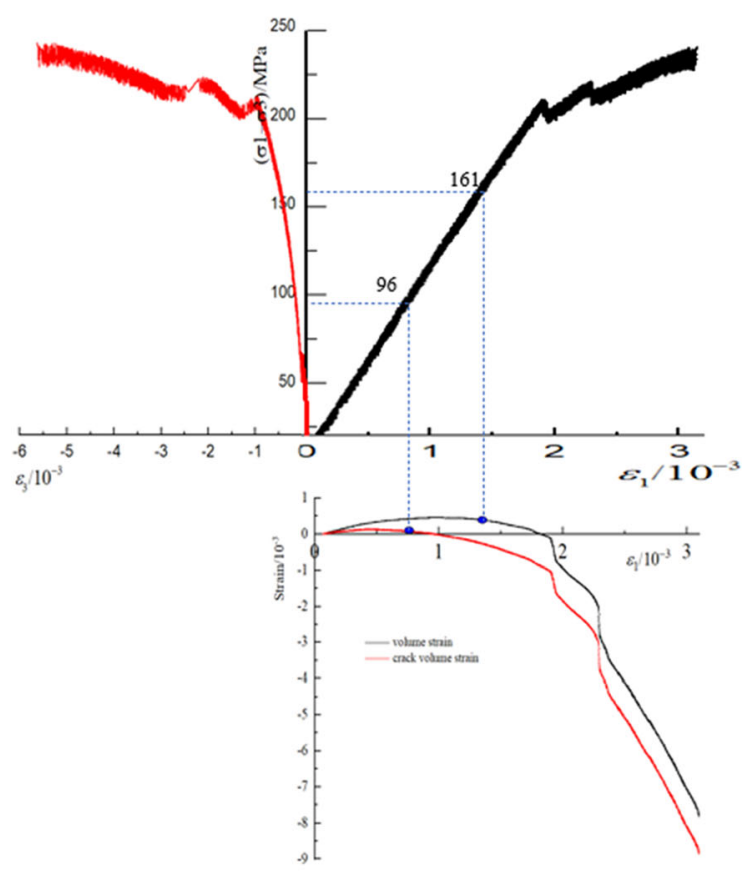

(B) Feldspar nonuniform development

Fig. 4 Stress-strain curves of different metagabbros

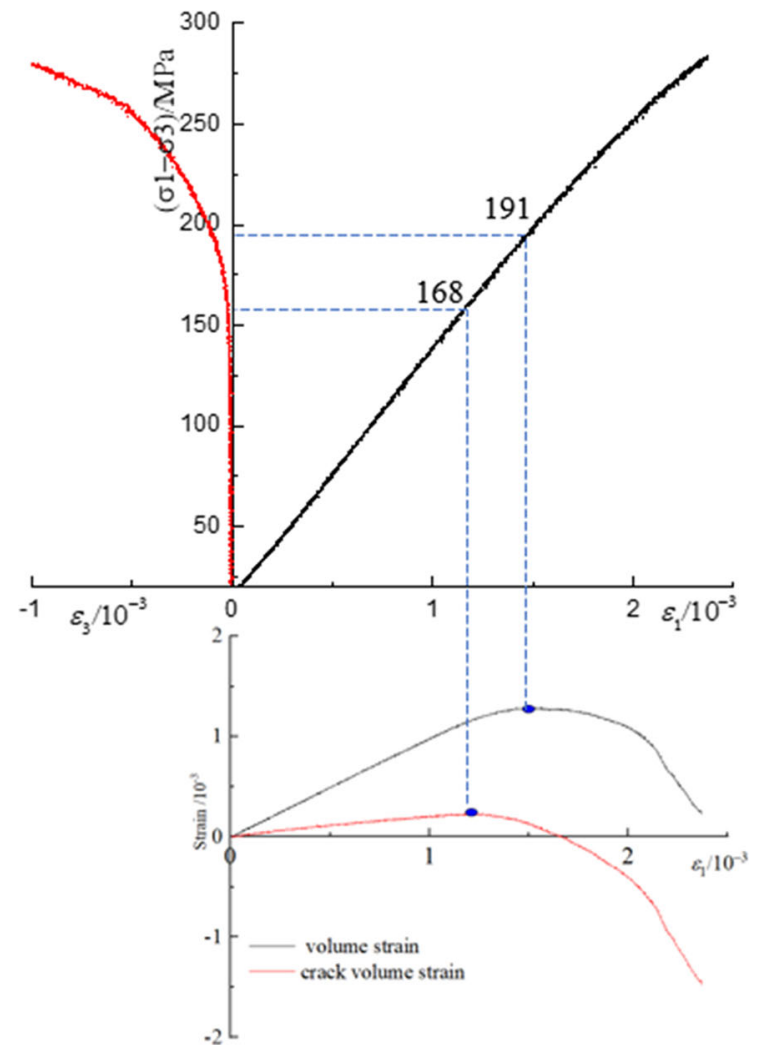

(C) Uniform feldspar development

Fig. 4 continued

propagation, indicating that the interior of the rock had been severely ruptured, but it still had a certain bearing capacity after internal structure adjustment.

\subsection{Characteristics of AE Absolute Energy in Different Metagabbros}

The absolute AE energy is the real reflection of the energy of AE impact signal, which can reflect the scale of rock internal fracture. The absolute energy unit of $\mathrm{AE}$ is attoJoules (aJ), and 1 aJ is equivalent to $10^{-18} \mathrm{~J}$. Figure 6 shows the curves of stress, AE absolute energy, and AE accumulative absolute energy with time under the hydraulic coupling of different metagabbros.

The AE absolute energy of metagabbro showed a sudden release of energy during instability failure. The peak of AE absolute energy for metagabbro samples $\mathrm{A}, \mathrm{B}$, and $\mathrm{C}$ was 4.27e6aj, 1.74e9aj, 1.44e7aj, respectively, exhibiting that metagabbro with feldspar mineral development showed sever damage. The 
Fig. 5 Stress-time-AE ringing count relationship of different metagabbros

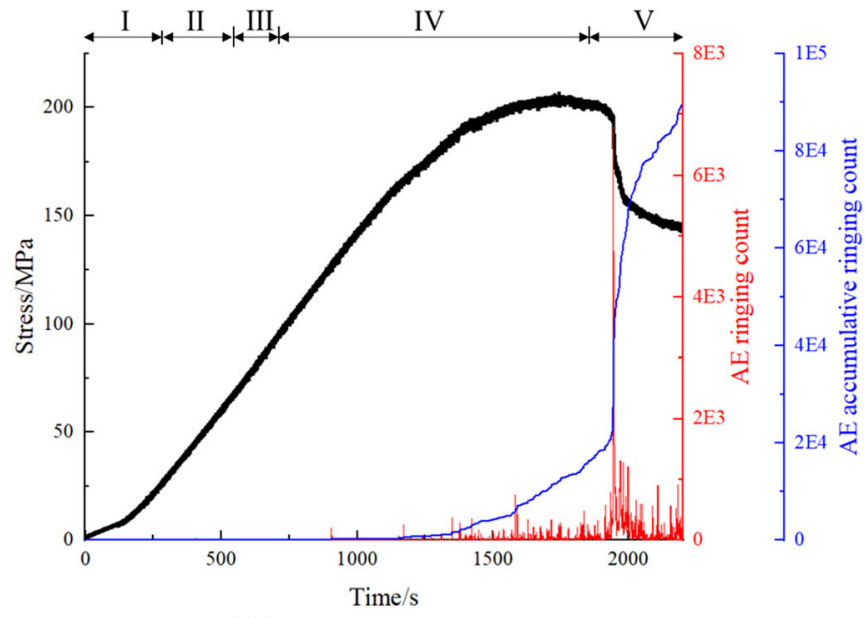

(A) Feldspar nondevelopment

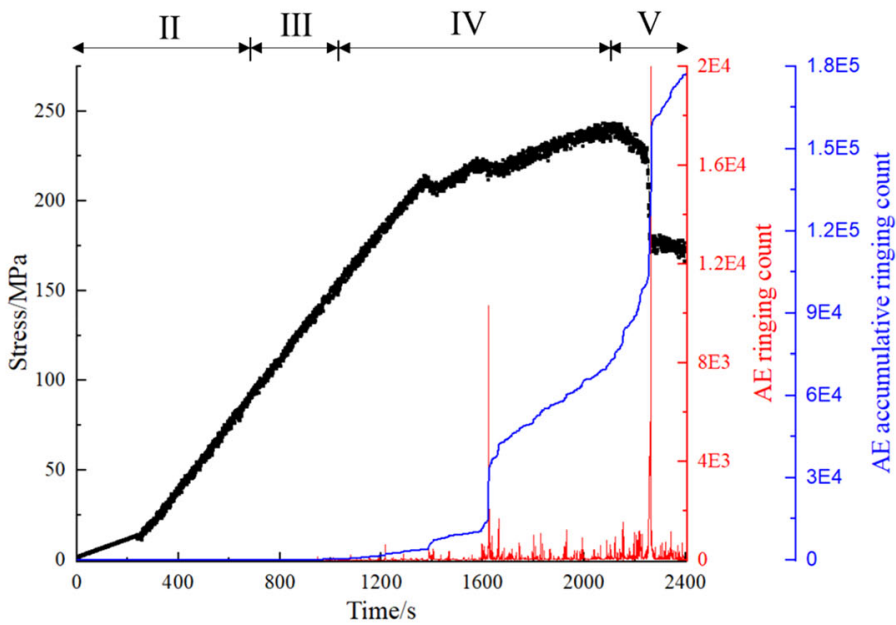

(B) Feldspar nonuniform development

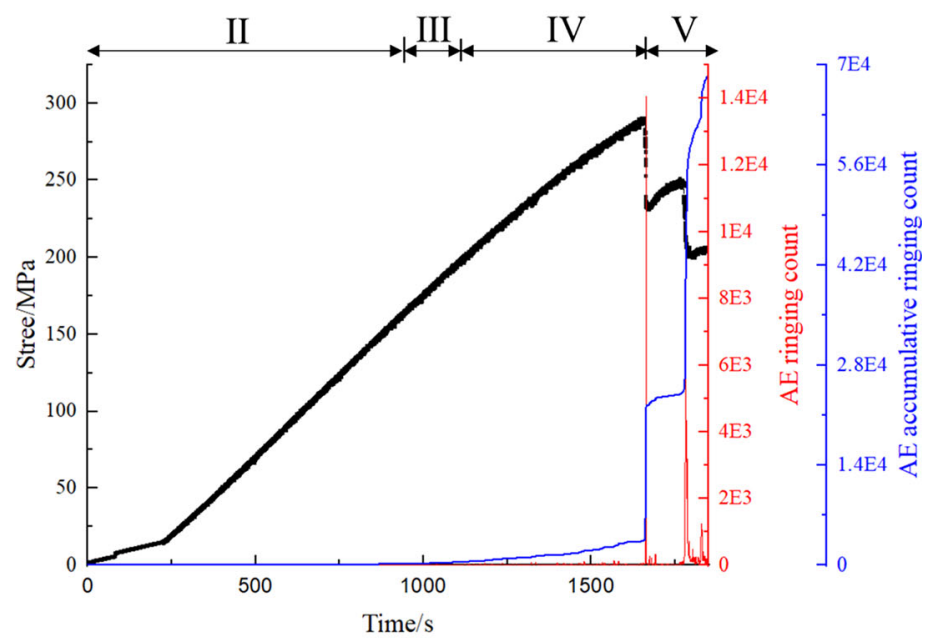

(C) Uniform feldspar development 
Fig. 6 Stress-time-AE

absolute energy relationship of different metagabbros

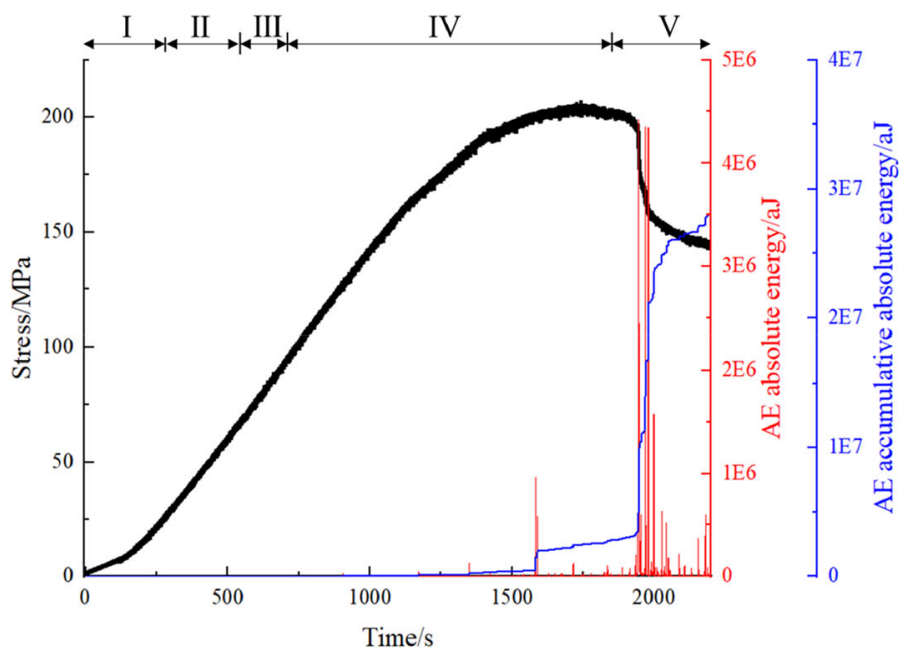

(A) Feldspar nondevelopment

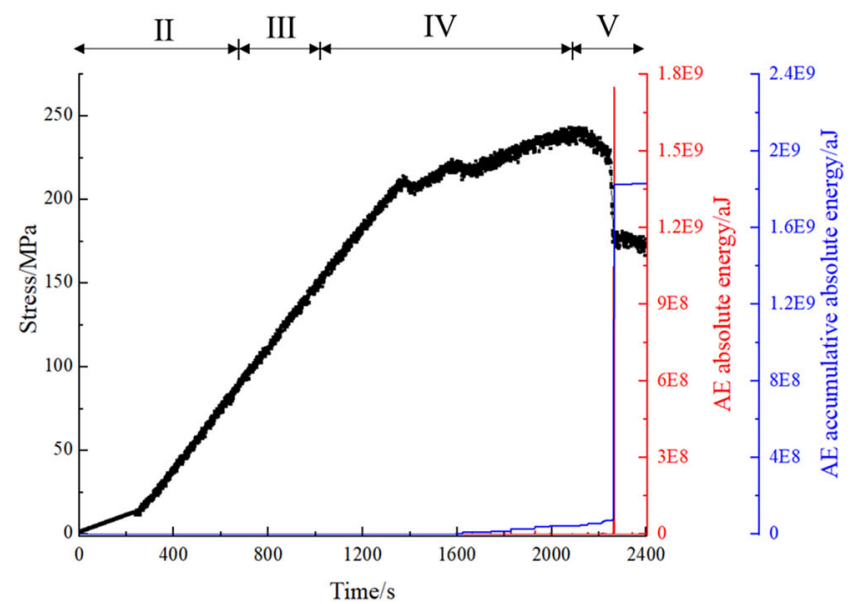

(B) Feldspar nonuniform development

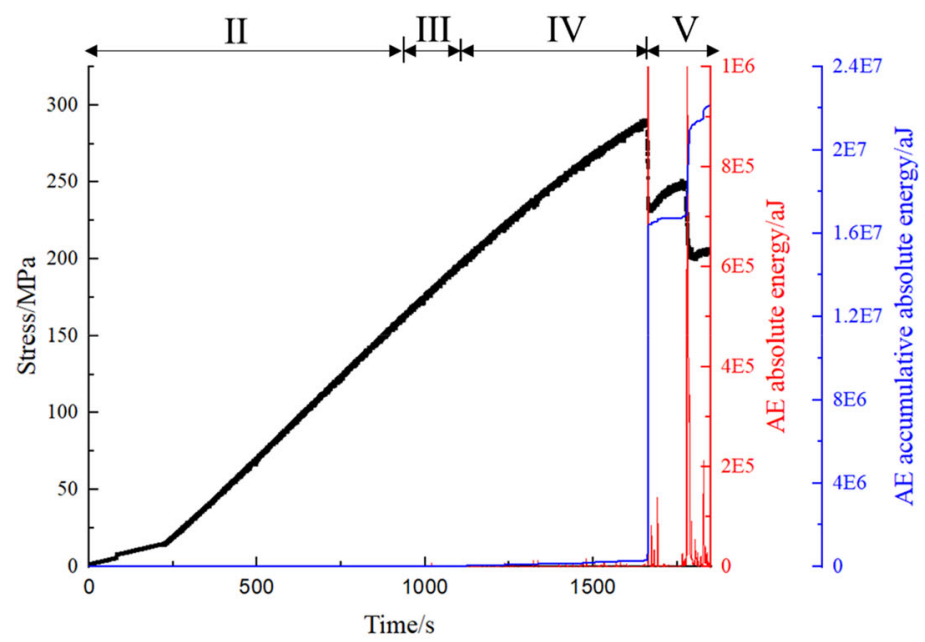

(C) Uniform feldspar development 
internal structures of metagabbro samples A and B were still constantly adjusted after reaching the peak stress, and their energy suddenly released until the formation of penetrating shear cracks. The AE accumulative energy of metagabbro sample $\mathrm{C}$ increased rapidly at the peak stress, and the internal energy accumulation effect was more obvious, and the brittle failure characteristics of the rock were stronger.

\section{Distribution Characteristics of AE Parameters in Different Metagabbros}

The AE signal parameter distribution analysis method is the statistical distribution analysis of the AE signal characteristic parameter. Distribution analysis can identify the characteristics of AE sources and evaluate the strength of AE sources to identify and predict the fractured state of different rocks (Du et al. 2020; Liu et al. 2019).

\subsection{Distribution Characteristics of AE Absolute Energy and Ringing Count}

Figure 7 shows the plot of the AE absolute energy and ringing count distribution of different metagabbros,

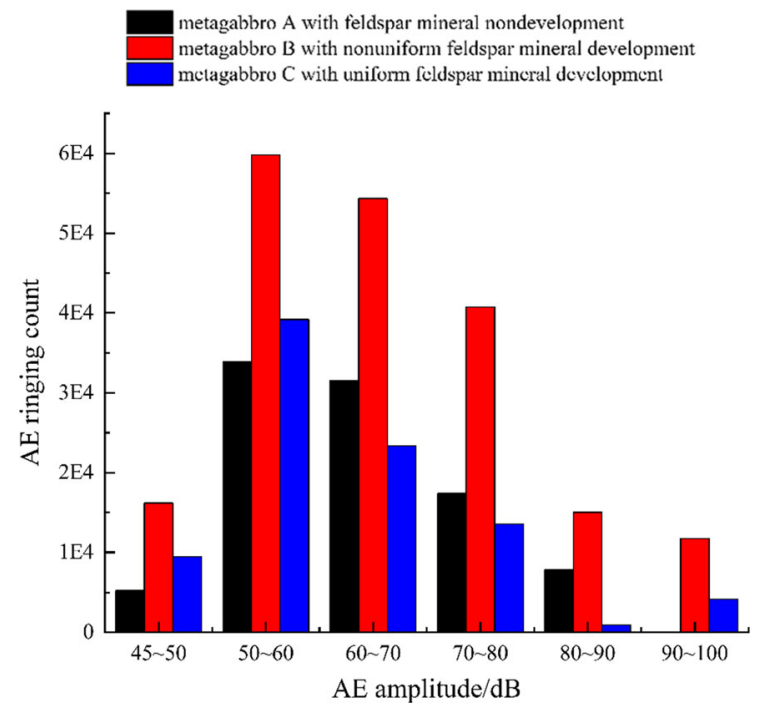

Fig. $8 \mathrm{AE}$ amplitude and $\mathrm{AE}$ ringing count distribution of different metagabbros

exhibiting $\Lambda$-type distribution trend. However, AE ringing counts of different metagabbro samples varied in the same $\mathrm{AE}$ absolute energy range. The $\mathrm{AE}$ absolute energy of metagabbro sample B was mainly concentrated on $0-5 \mathrm{e} 3 \mathrm{aJ}$. The AE absolute energies of metagabbro samples $\mathrm{A}$ and $\mathrm{C}$ were mostly between

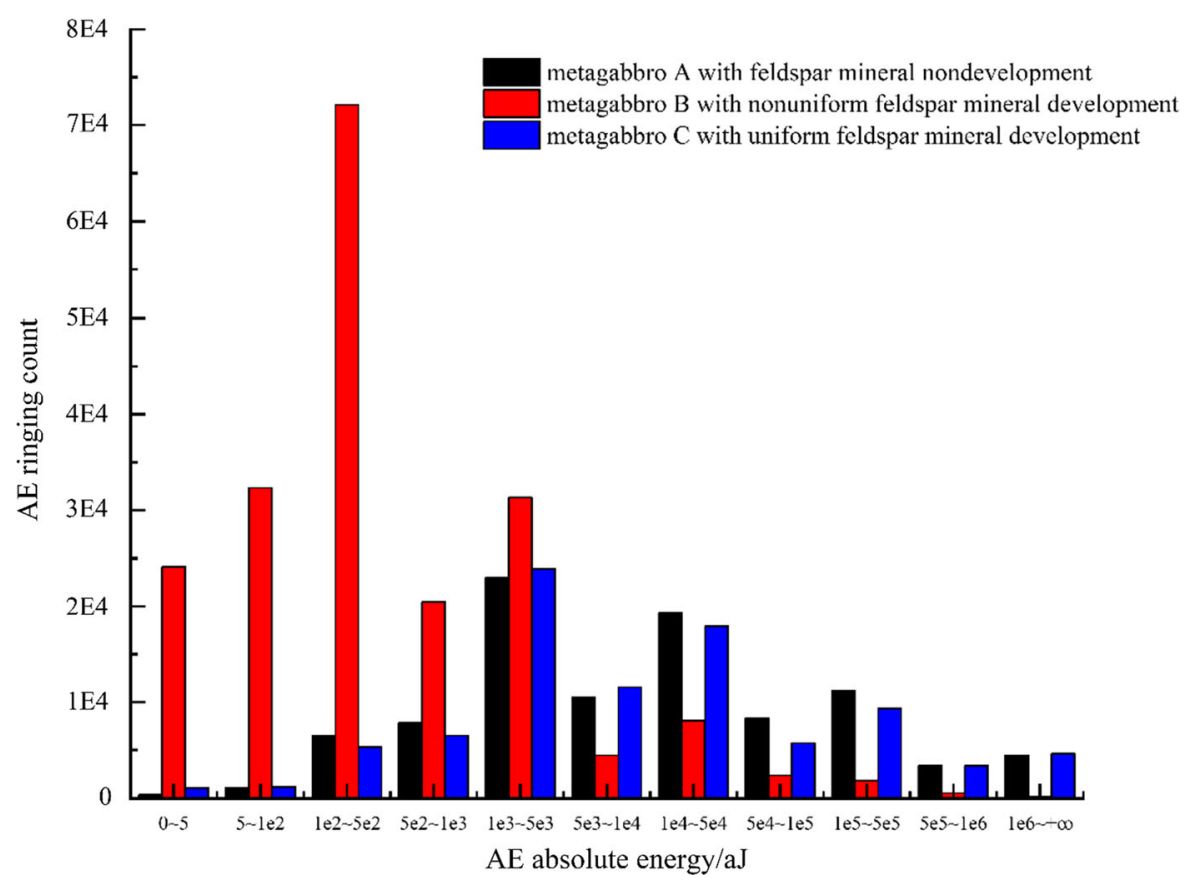

Fig. 7 AE absolute energy and ringing count distribution of different metagabbros 
$5 \mathrm{e} 2-5 \mathrm{e} 4 \mathrm{aJ}$. It was observed that the $\mathrm{AE}$ ringing count of metagabbro sample $B$ was primarily centered in the low energy range, whereas a large number of $\mathrm{AE}$ ringing counts still occurred in the high energy range of metagabbro sample $\mathrm{C}$, demonstrating that the uniformity of mineral distribution is related to the AE absolute energy distribution.

\subsection{Distribution Characteristics of AE Amplitude and AE Ringing Count}

The AE amplitude is directly associated with the event size and is not affected by the threshold. As shown in Fig. 8, the AE amplitudes of different metagabbros were mainly in the range $50-80 \mathrm{~dB}$. Compared to metagabbro sample A, metagabbro samples $B$ and $C$ had a large number of $\mathrm{AE}$ ringing counts occurring in the AE amplitude range $90-100 \mathrm{~dB}$, demonstrating that with increasing felspar mineral content in metagabbro, the rock sample released stronger $\mathrm{AE}$ signals, corresponding to the absolute energy released by AE. Hence, the wave source type was determined by the $\mathrm{AE}$ ringing count corresponding to high amplitude.

\subsection{AE Duration and AE Ringing Count Distribution of Different Metagabbros}

As shown in Fig. 9, the duration of metagabbro sample A was mainly less than $500 \mu \mathrm{s}$, and the ringing count of the rock was highest in the $\mathrm{AE}$ duration range $0-50 \mu$ s. The AE duration of metagabbro samples B and $\mathrm{C}$ was largely concentrated in $1 \mathrm{e} 3-1 \mathrm{e} 4 \mu \mathrm{s}$, and the ringing count of those rocks was highest in the $\mathrm{AE}$ duration range $2 \mathrm{e} 3-5 \mathrm{e} 3 \mu \mathrm{s}$ (Fig. 9). Furthermore, the ringing count of metagabbro sample $\mathrm{B}$ was visibly higher than that of metagabbro sample $C$ in the same duration, revealing that with increasing feldspar mineral content in metagabbro, the AE signals showed longer duration characteristics.

\section{Characteristics of AE Peak Frequencies and Permeability in Different Metagabbros}

Different metagabbros were subjected to AE test utilizing two acoustic emission channels of low frequency and high frequency, guaranteeing that signals of higher and lower frequencies could be gathered. As illustrated in Fig. 10, the low-frequency and high-frequency signals were combined to generate

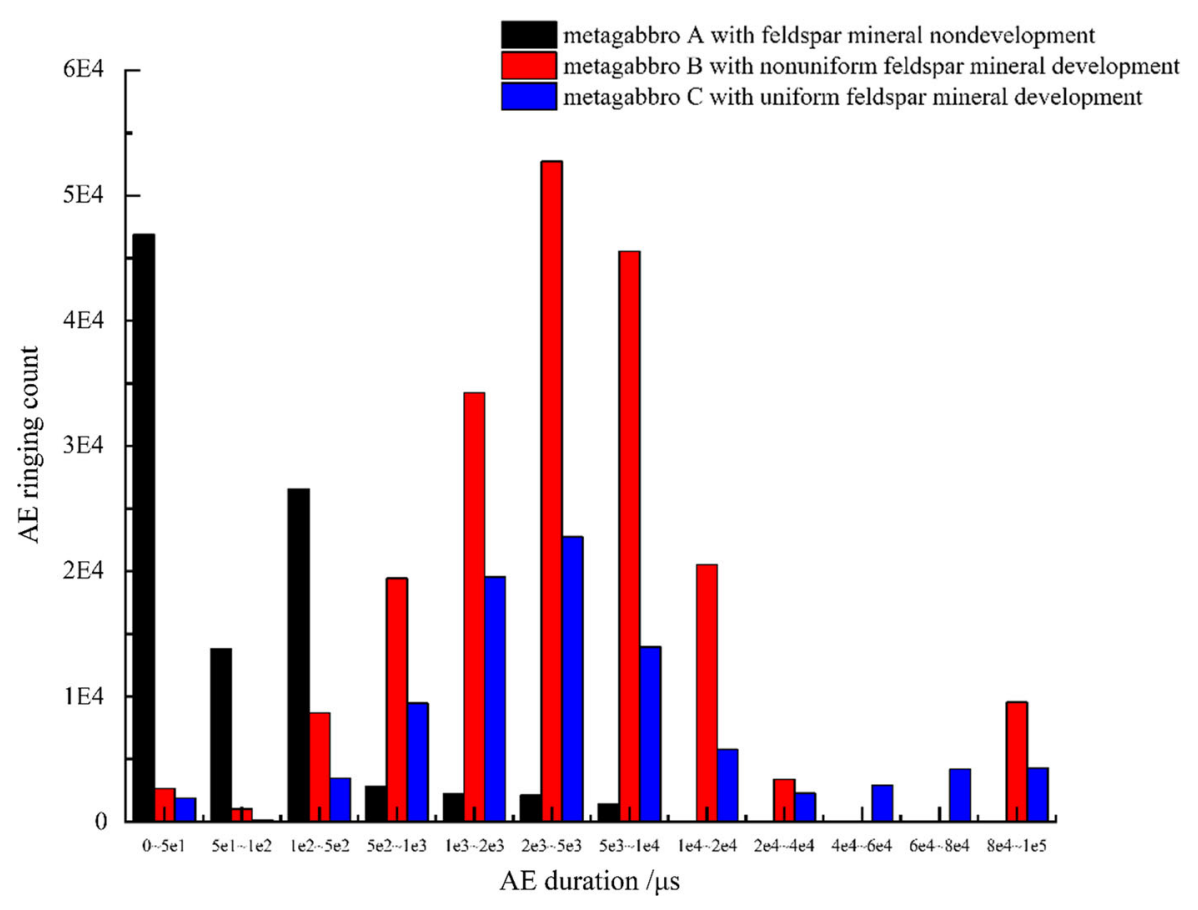

Fig. 9 AE duration and ringing count distribution of different metagabbros 
Fig. 10 Stress-time-AE peak-frequency relationship of different metagabbros

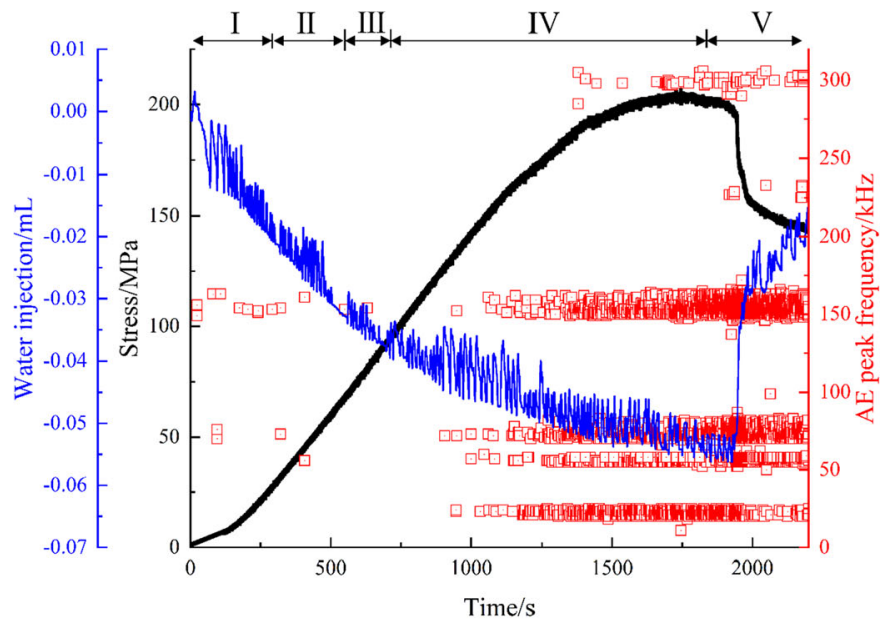

(A) Feldspar nondevelopment

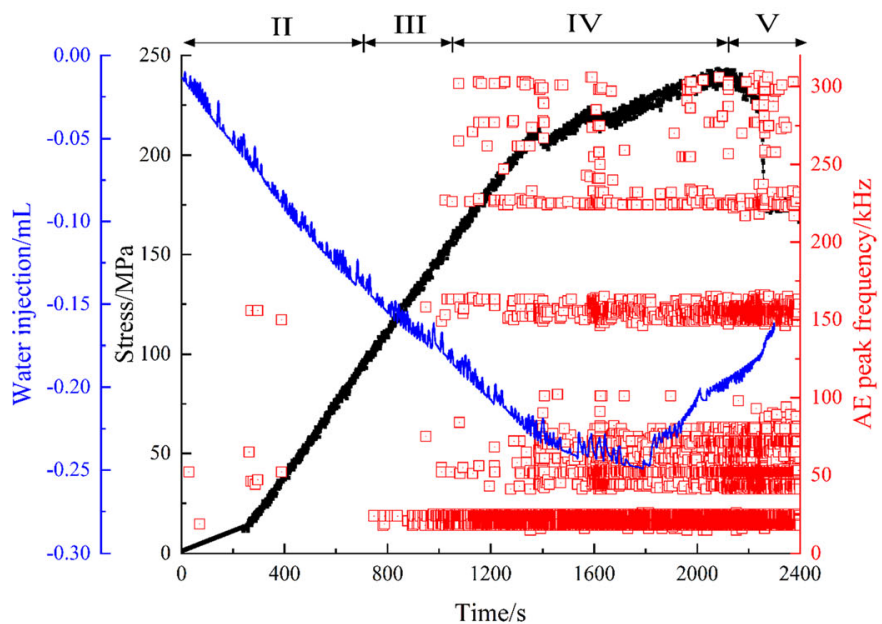

(B) Feldspar nonuniform development

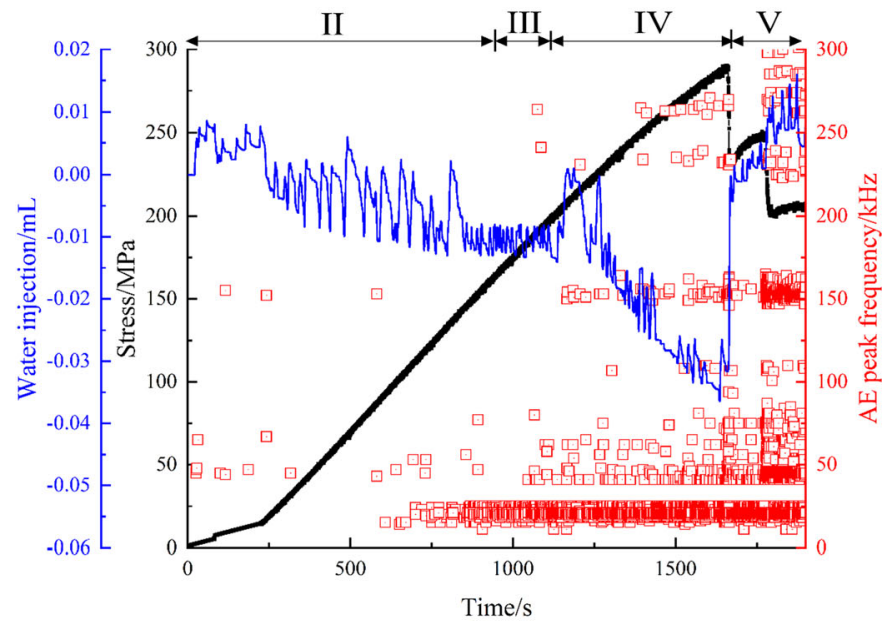

(C) Uniform feldspar development 
the peak frequency, stress, and water injection with time.

The AE peak frequencies of the three rocks were primarily centered in the range 40-60 and $145-155 \mathrm{kHz}$ in the elastic stages. As the loading increased, the AE signals showed higher and lower frequencies. In the unstable crack propagation stage, metagabbro sample A exhibited four AE peak frequency ranges 20-25, 55-80, 145-165, and 295-305 kHz, while metagabbro samples B and C displayed five frequency ranges 20-25, 55-80, 145-165, 235-245, 295-305 kHz. Metagabbro sample A also showed a frequency band in the range $235-245 \mathrm{kHz}$ in the post-peak stage, as a result of continuous friction and fracture of minerals on the shear surface. Metagabbro sample B had higher AE peak frequency signals. Metagabbro samples A and C merely had higher high-band AE peak frequencies near the peak destruction. The characteristic highfrequency signal released in the unstable extension of cracks became increasingly visible as the interior mineral development grew to be more nonuniform. This was of great significance for distinguishing the critical fracture signal characteristics of rocks.

The trend of water injection reflects the development of fractures in rock, which indirectly reflects the permeability characteristics. The permeability of intact metagabbro is extremely low, and the cracks inside the rock are not developed, making water infiltration difficult. In the elastic stage, the pore water inside the rock was continuously squeezed out, and the permeability was continuously reduced. The amount of water reflects the degree of development of the pores and microcracks in the rock. The extrusion draining contents of metagabbro samples $\mathrm{A}, \mathrm{B}$, and $\mathrm{C}$ were $0.04,0.17$, and $0.02 \mathrm{~mL}$, respectively, exhibiting that the metagabbro with nonuniform feldspar mineral development had more pores and microcracks. Metagabbro samples $\mathrm{A}$ and $\mathrm{C}$ were at the extrusion draining stage before rupture. With the internal extrusion adjustment, the saturated pore water in the rock continually forced out, and there was no penetrating crack. However, the stress concentration occurred in the internal fractures of the metagabbro sample B during the unstable propagation stage of cracks, resulting in massive cracks and water infiltration. The water infiltration indicates higher permeability of the rock, which demonstrated that the permeability of the rocks is highly correlated with the uniformity of mineral development.

\section{Conclusion}

In summary, the AE test of three metagabbros with different mineral development was conducted under hydraulic coupling. The characteristic parameter of acoustic emission signals and their correlation characteristics were explored. The following conclusions are drawn.

(1) The mechanical properties of metagabbro samples were closely linked to feldspar minerals. The metagabbro with feldspar mineral development had much higher peak strength, initiation strength, damage strength, and elastic modulus than metagabbro without feldspar mineral development, with lower Poisson ratio.

(2) The AE signals of different metagabbros mainly occurred in the unstable extension stage of the fracture. The AE accumulative absolute energy of metagabbro without feldspar mineral development had a clear step jump law before the failure. The AE accumulative ringing count of metagabbro with nonuniform feldspar mineral development had a clear jump law before the failure. However, the AE signal released by metagabbro with uniform feldspar mineral development did not follow this law, and its brittleness and energy accumulation are greater.

(3) The uniformity of mineral distribution related to the AE absolute energy distribution. Metagabbro with nonuniform feldspar mineral development was mainly concentrated in the low energy range. With increasing feldspar mineral content in metagabbro, the AE signals showed a longer duration and a higher amplitude.

(4) In the elastic stage, the acoustic emission peak frequency of metagabbro primarily distributed in the ranges $40-60$ and $145-155 \mathrm{kHz}$. In the plastic stage, metagabbro with feldspar mineral nondevelopment exhibited four peak frequency ranges, and that with feldspar mineral development displayed five frequency ranges. The metagabbro with nonuniform feldspar mineral development had more pores and microcracks than that with uniform mineral development. 
During the unstable crack propagation stage, metagabbro with uniform mineral development did not show water infiltration, whereas that with nonuniform mineral development exhibited water infiltration before the rupture.

\begin{abstract}
Authors' contributions Conceptualization, HJ; methodology, $\mathrm{TZ}$ and $\mathrm{HJ}$; formal analysis, TZ, XS, and DQ; resources, HJ; writing - original draft preparation, $\mathrm{TZ}$ and $\mathrm{HJ}$; visualization, $\mathrm{TZ}, \mathrm{ZZ}$, and JL; funding acquisition, TZ and HJ. All the authors have read and agreed to the published version of the manuscript.
\end{abstract}

Funding Open Access funding enabled and organized by Projekt DEAL. This study was supported by the National Key R\&D Program of China (No. 2016YFC0600801), the Major Scientific and Technological Innovation Project of Shandong Province (No. 2019SDZY02, No. 2019SDZY05), and China Scholarship Council (No. 202006460024).

Availability of data and material The data are available from the first author upon request.

Code availability Not applicable.

\section{Declarations}

Conflict of interest The authors declare no conflict of interest.

Open Access This article is licensed under a Creative Commons Attribution 4.0 International License, which permits use, sharing, adaptation, distribution and reproduction in any medium or format, as long as you give appropriate credit to the original author(s) and the source, provide a link to the Creative Commons licence, and indicate if changes were made. The images or other third party material in this article are included in the article's Creative Commons licence, unless indicated otherwise in a credit line to the material. If material is not included in the article's Creative Commons licence and your intended use is not permitted by statutory regulation or exceeds the permitted use, you will need to obtain permission directly from the copyright holder. To view a copy of this licence, visit http://creativecommons.org/licenses/by/4.0/.

\section{References}

Cai MF, Xue DL, Ren FH (2019) Current status and development strategy of metal mines. Chin J Eng 41(04):417-426

Cowie S, Walton G (2018) The effect of mineralogical parameters on the mechanical properties of granitic rocks. Eng Geol 240:204-225

Du K, Li X, Tao M et al (2020) Experimental study on acoustic emission (AE) characteristics and crack classification during rock fracture in several basic lab tests. Int J Rock Mech Mining Sci 133:104411
Hu SH, Chen YF, Zhou CB (2014) Experimental study and meso-mechanical analysis of Beishan granite permeability. J Rock Mech Eng 33(11):2200-2209

Ji HG, Lu X (2015) Characteristics of acoustic emission and rock fracture precursors of granite under conventional triaxial compression. Chin J Rock Mech Eng 34(4):694-702

Ji HG, Chen B, Sun LH et al (2015) Research on the acoustic emission of weakly consolidated sandstone under uniaxial compression in Hongqinghe Coal Mine. Metal Mine 10:56-61

Li HG, Li HM (2017) Mechanical properties and acoustic emission characteristics of thick hard roof sandstone in Shendong coal field. Int J Coal Sci Technol 4(2):147-158

Li XB, Zhou J, Wang SF et al (2017) Review and practice of deep mining for solid mineral resources. Chin J Nonferrous Met 27(06):1236-1262

Li HM, Wang KL, Li HG et al (2018) Study on mechanical and acoustic emission characteristics of weakly cementation sandstone in Shendong coal field. J Mining Safety Eng 33(4):843-851

Liu ZQ, Zhang Q (2008) A review on the state of art of the saturated seepage-stress coupling models in rock mass. Adv Mech 05:585-600

Liu XS, Wang K, Xu M (2018) Permeability evolution of lowpermeability reservoir sandstone considering hydraulicmechanical-damage coupling effect during gradual fracturing process. Chin J Eng 40(09):1584-1592

Liu S, Li X, Li Z et al (2019) Energy distribution and fractal characterization of acoustic emission (AE) during coal deformation and fracturing. Measurement 136:122-131

Martin CD, Chandler NA et al (1994) The progressive fracture of Lac du Bonnet granite. Int J Rock Mech Mining Sci Geomech Abstracts 31(6):643-659

Pei F, Ji HG, Zhang TZ (2019) Detection of cracking levels in granite by AE signals under uniaxial compression. Geotech Geol Eng 37(4):2565-2576

Song ZY, Ji HG, Jiang $\mathrm{H}$ et al (2018) Influence of wettingdrying cycles on acoustic emission characteristics and microstructure deterioration of weak cementation stratum. J China Coal Soc 43(S1):96-103

Song ZY, Tan J, Wang YZ et al (2019) Experiment study on acoustic emission character of weakly cementation sandstone with different particle size under uniaxial loading. Mine Const Technol 40(3):31-35

Song ZY, Ji HG et al (2020) Study on acoustic emission signal sources and critical failure precursors of weakly consolidated sandstone with different grain sizes. J China Coal Soc 45(12):4028-4036

Ündül Ö (2016) Assessment of mineralogical and petrographic factors affecting petro-physical properties, strength and cracking processes of volcanic rocks. Eng Geol 210:10-22

Wang JN, Peng SP, Meng ZP (2001) Permeability rule in full strain-stress process of rock under triaxial compression. J Univ Sci Technol Beijing 06:489-491

Wang GR, Xue DJ, Gao HL et al (2012a) Study on permeability characteristics of coal rock in complete stress-strain process. J China Coal Soc 37(01):107-112

Wang B, Zhu JB, Yan P et al (2012b) Damage strength determination of marble and its parameters evaluation based on damage control test. Chin J Rock Mech Eng 31(Supp. 2):3967-3973 
Wang Y, Li X, Wu YF et al (2014) Research on relationship between crack initiation stress level and brittleness indices for brittle rocks. Chin J Rock Mech Eng 33(2):264-275

Wang XY, Zhou HG, Zhong JC et al (2018) Study on energy evolution and permeability characteristics of deep coal damage under triaxial cyclic loading and unloading conditions. Chin J Rock Mech Eng 37(12):2676-2684

Xie HP (2019) Research review of the state key research development program of China: deep rock mechanics and mining theory. J China Coal Soc 44(05):1283-1305

Zeng P, Liu YY, Ji HG et al (2017) Coupling criteria and precursor identification characteristics of multi-band acoustic emission of gritstone fracture under uniaxial compression. Chin J Geotechn Eng 39(3):509-517

Zhang LM, Ma SQ, Ren MY et al (2015) Acoustic emission frequency and $b$ value characteristics in rock failure process under various confining pressures. Rock Soil Mech 34(10):2057-2063

Zhang YL, Fu CC, Wang YX et al (2016) Tests on hydro-mechanical coupling characteristics of fractured limestone in complete stress-strain process. Chin J Rock Mech Eng 35(S2):3763-3773

Zhang Z, Xie H, Zhang R et al (2019a) Deformation damage and energy evolution characteristics of coal at different depths. Rock Mech Rock Eng 52(5):1491-1503
Zhang CH, You S, Ji HG et al (2019b) Hydraulic properties and energy dissipation of deep hard rock under H-M coupling and cycling loads. Thermal Sci 23(S3):S943-S950

Zhang PS, Zhao CY, Hou JQ et al (2020a) Experimental Study on permeability characteristics of deep Sandstone under high temperature and different water pressure. Chin J Rock Mech Eng 39(6):1117-1128

Zhang PS, Zhao CY, Hou JQ et al (2020b) Experimental study on seepage characteristics of deep sandstone under temperature-stress-seepage coupling conditions. Chin J Rock Mech Eng 39(10):1957-1974

Zhang PS, Hou JQ, Zhao CY et al (2020c) Experimental study on seepage characteristics of red sandstone with different confining pressure and different damage degree. Chin J Rock Mech Eng 39(12):2405-2415

Zhao Y, Liu S, Zhao GF et al (2014) Failure mechanisms in coal: dependence on strain rate and microstructure. J Geophys Res Solid Earth 119(9):6924-6935

Zhu ZQ, Sheng Q, Leng XL et al (2007) Study of crack initiation mechanism of three gorges granite. Chin J Rock Mech Eng 26(12):2570-2575

Publisher's Note Springer Nature remains neutral with regard to jurisdictional claims in published maps and institutional affiliations. 